\title{
Sweat Function in Babies with Defects of the Central Nervous System
}

\author{
K. G. FOSTER, E. N. HEY, and BRIDGET O'CONNELL \\ From the M.R.C. Environmental Physiology Unit, London School of Hygiene and Tropical Medicine, and the Neonatal \\ Research Group, The London Hospital Medical College, London
}

\begin{abstract}
Foster, K. G., Hey, E. N., and O'Connell, B. (1971). Archives of Disease in Childhood, 46, 444. Sweat function in babies with defects of the central nervous system. Sweat function has been studied as part of the full neurological examination of 50 full-term infants with malformation of the central nervous system. 26 of the children were less than 1 month old at the time of examination, and a further 10 were less than 3 months old. In those infants in whom the response to thermal stimulation was equivocal, the local response to $20 \mu \mathrm{g}$ intradermal acetylcholine was also studied. Sweat function was normal above the level of the spinal lesion in all of the 24 infants with a lumbar meningomyelocele, but there was virtually no response to thermal or chemical stimulation of the thigh in the 9 infants with a flaccid paralysis of the legs. In 8 infants born with gross disorganization of the basal ganglia or brainstem (as later confirmed by necropsy) there was no sweat response anywhere to either thermal or chemical stimulation. Similar generalized anhidrosis was found in 4 other infants with severe hydrocephalus.

These studies are consistent with the view that the eccrine sweat glands over most of the body only develop the ability to respond to acetylcholine if functionally innervated in utero. Sweat tests can provide information of prognostic value in full-term infants with defects of the CNS at birth.
\end{abstract}

The normal full-term baby sweats in warm surroundings when the rectal temperature rises above $37.5^{\circ} \mathrm{C}$, even on the day of birth, and often sweats at a lower temperature than this when a few days old (Hey and Katz, 1969). The response is most marked on the face and forehead and is often difficult to detect on the limbs, though the glands here respond unequivocally to intradermal acetylcholine or pilocarpine. Babies of short gestation are also capable of sweating to a limited extent, unless born more than 8 weeks before term, but the response is frequently small and largely limited to the head; in babies born more than 2 weeks before term the glands on the limbs frequently fail to respond either to warmth or to direct chemical stimulation (Foster, Hey, and Katz, 1968, 1969a; Behrendt and Green, 1969; Green and Behrendt, 1969, 1970). There is histological evidence that this pattern of response is probably due to regional differences in the timing of glandular development.

Tests of thermal sweat function have a recognized

Received 9 February 1971. role in the neurological assessment of the adult patient, but similar tests are seldom attempted in infants or young children. This is partly because the response to thermal stimulation can be difficult to elicit and patchy in distribution, especially during the first few weeks of life. As a result of earlier observations (Cross et al., 1971), we came to believe that sweat glands might only develop the ability to respond to direct chemical stimulation if functionally innervated in utero. It seemed conceivable that, if this were true, tests of the sweat response to direct chemical stimulation might prove easier to perform, and simpler to interpret, and $N$ might also acquire some clinical value. The $N$ present study was undertaken in order to assess this possibility.

A preliminary report of this work was published in 1969 (Foster, Hey, and O'Connell, 1969b).

\section{Methods}

Sweat responses to thermal stimuli. The presence or absence of a thermal sweat response was judged by placing starch paper impregnated with 


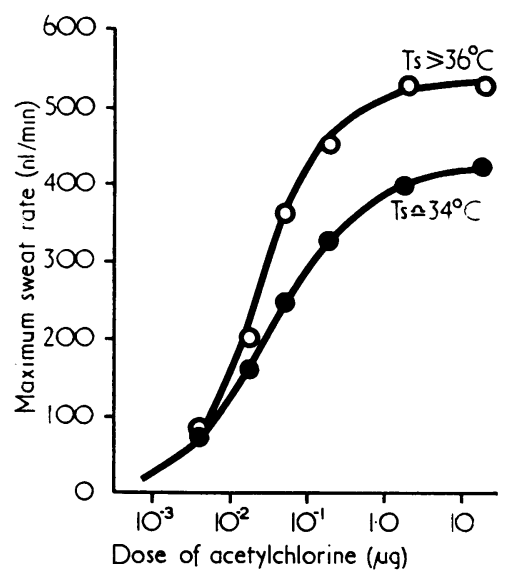

(a)

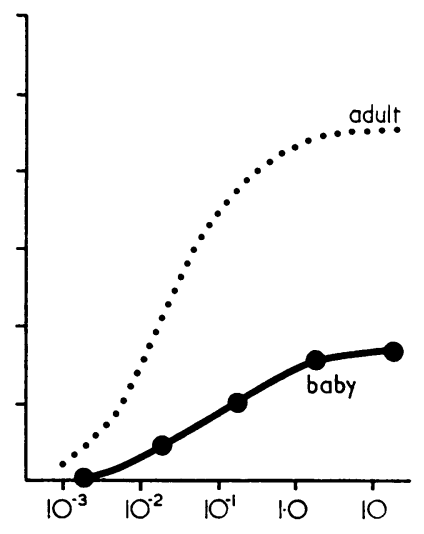

(b)

FIG. 1.-The sweat response on the forearm to different doses of intradermal acetylcholine in $0.2 \mathrm{ml}$ saline recorded using a capsule $1 \mathrm{~cm}$ in diameter. (a) The effect on skin temperature $\left(T_{s}\right)$ on the maximal sweat response to acetylcholine in a healthy young adult. A curve of the type $y=a /\left(1+e^{b-e x}\right)$ has been fitted to both sets of data (Foster, 1971).

(b) A typical dose-response curve for a baby of 41 weeks' gestation when 10 days old.

iodine on the skin surface for 10 seconds.* The response was only recorded as negative if no sweat was detected when rectal temperature had reached $37 \cdot 8^{\circ} \mathrm{C}$ in babies under 6 months old, and $37.5^{\circ} \mathrm{C}$ in older children.

Sweat response to chemical stimuli. Where the thermal response was equivocal the sweat response to chemical stimulation was also examined. The presence or absence of a response was judged in five of the early studies using the pilocarpine iontophoresis technique of Gibson and Cooke (1959). In all the later studies quantitative estimates of the response to intradermal acetylcholine were obtained using the technique of Foster and Weiner (1967); the response was only recorded as negative if no sweat was detected under the ventilated capsule after five tests with either 2 or $20 \mu \mathrm{g}$ acetylcholine in $0.2 \mathrm{ml}$ saline. Care was taken to have the baby in warm surroundings and to maintain rectal temperature between 36.8 and $37.2{ }^{\circ} \mathrm{C}$, but no attempt was made to warm the test solutions to body temperature before use, or to maintain a constant skin temperature at the site under test.

Sweat gland counts. The number of functional sweat glands following stimulation with acetylcholine was assessed during some of the studies using the technique of Sutarman and Thomson (1952)

Pilomotor sympathetic axon reflex. The integrity of part of the postganglionic sympathetic nerve plexus was tested where appropriate by injecting $20 \mu \mathrm{g}$ acetylcholine or $2 \mu \mathrm{g}$ nicotine in $0.2 \mathrm{ml}$ saline intradermally into the arm or leg and looking for the pilomotor

\footnotetext{
\These papers can be prepared by enclosing sheets of absorbent starch rich paper above a few crystals of iodine in a tin and applying very gentle warmth until some of the iodine vapourizes. We have used snow white Dover opaque offset cartridge paper from Wiggins Teape Ltd.
}

axon reflex that this normally elicits (Coon and Rothman, 1940; Rothman and Coon, 1940).

\section{Results}

Normal response to stimulation. It is always possible to detect sweat on the forehead and trunk of the normal full-term baby using starchiodine paper following moderate thermal stimulation, but it is often difficult to detect any sweat on the limbs. The response to chemical stimulation is less equivocal though the magnitude of the response is variable.

Tests showed that babies with lumbar meningomyelocele (but without evidence of overt intracranial abnormality at birth) responded to acetylcholine in the same way as healthy term babies (Foster et al., 1969a) above the level of the spinal lesion. Dose-response curves in healthy control subjects (Fig. 1) indicated that $2 \mu \mathrm{g}$ intradermal acetylcholine evoked something approaching a maximum rate of sweat secretion from nearby glands. Nevertheless, while there was no significant difference between the mean response to $2 \mu \mathrm{g}$ and $20 \mu \mathrm{g}$ acetylcholine (Table I), a paired variate test confirmed that there was normally a slightly greater response to $20 \mu \mathrm{g}$ with the test procedure adopted both in the babies and in the adult controls $(\mathrm{P}<0 \cdot 05)$. A test dose of $20 \mu \mathrm{g}$ was therefore employed throughout the present study in order to stimulate maximum sweat output.

The maximum response to acetylcholine was often particularly small in babies less than 3 months old, but counts showed that this was largely because only part of the skin under the capsule 
TABLE I

Maximum Sweat Response (nl/min) to $2 \mu \mathrm{g}$ and $20 \mu \mathrm{g}$ Acetylcholine in $0.2 \mathrm{ml}$ Saline (Mean $\pm S E M)$

\begin{tabular}{c|c|c}
\hline & \multicolumn{2}{|c|}{ Dose } \\
\cline { 2 - 3 } Subjects & $2 \mu \mathrm{g}$ & $20 \mu \mathrm{g}$ \\
\hline 10 infants $<12 \mathrm{wk}$ & $176 \pm 37$ & $208 \pm 51$ \\
5 infants 6-18 mth & $347 \pm 50$ & $404 \pm 77$ \\
10 healthy young adults & $507 \pm 92$ & $542 \mathrm{t2}$ \\
& & \\
\hline
\end{tabular}

These responses were recorded using a ventilated capsule $1 \mathrm{~cm}$ in diameter on the arm. All the babies studied had had lumbar meningomyeloceles at birth.

was stimulated by the test procedure employed (Table II). The estimated functional sweat gland density in the skin fell nearly fivefold between birth and early adult life, while the calculated mean maximum sweat output per gland quadrupled in this time (Table II).

It has recently become clear that the magnitude of the response to intradermal acetylcholine is much augmented when the skin is warm (Fig. 1). In one adult who was studied four times the maximum response fell by $20 \pm 4 \%$ (mean \pm SEM) when skin temperature fell below $36^{\circ} \mathrm{C}$. Care was taken during the present study to employ reasonably comparable thermal conditions for each subject, but no attempt was made to maximize the response to acetylcholine by monitoring skin temperature or blood flow.

Babies with congenital defects of CNS. We have studied sweat function in 50 babies who were born with serious defects of central nervous system. This work was performed in hospital as part of the overall assessment of each child's neurological condition. In babies with a spinal defect, sweat function was assessed for comparative purposes both above and below the level of the lesion.
Anencephaly. 4 term or postmature female anencephalic babies were studied when 1 to 3 days old. There was no thermal sweat response anywhere on the body and no response to tests with pilocarpine iontophoresis on the arm or leg (the only sites examined). These babies died within a week of birth.

Hydrancephaly. One 2-year-old grossly retarded boy in whom hydrancephaly was diagnosed about 3 months after birth had no thermal sweat response. There was no sweat response to intradermal acetylcholine on the arm or leg (the only sites tested), but there was a clear pilomotor response.

Encephalocele. 9 babies have been studied. 4 babies with a small occipital encephalocele sweated normally as did one baby with a small glabellar encephalocele. 4 mature infants with a large herniating occipital mass and associated microcephaly were examined in greater detail (Cross et al., 1971); 3 appeared to exert no control over their body temperature and showed no sweat response to chemical stimulation, but temperature regulation was normal in the fourth infant, as was the sweat response to thermal and chemical stimulation. No operative treatment was attempted in these 4 babies who died before they were 5 months old (Cross et al., 1971: Cases 4-7).

Hydrocephalus. 4 term babies have been studied who presented with hydrocephalus at birth. No other congenital abnormalities were detected. No sweat response to either thermal or chemical stimulation could be detected in 3 of these babies, and the response in the fourth infant was severely reduced.

In 6 other term babies head circumference was normal at birth and hydrocephalus only became evident 3 or more weeks after birth. Sweating was normal in 5 of these babies but, in a sixth infant who presented with gross hydrocephalus at

\section{TABLE II}

Skin Sweat Gland Density and Sweat Response on Forearm under Capsule $1 \mathrm{~cm}$ in Diameter after Stimulation with $20 \mu \mathrm{g}$ Acetylcholine in $0.2 \mathrm{ml}$ Saline (Mean $\pm S E M$ )

\begin{tabular}{|c|c|c|c|c|c|c|}
\hline Subjects & $\begin{array}{c}\text { Mean } \\
\text { Body Surface } \\
\text { Area } \\
\left(\mathrm{m}^{2}\right)\end{array}$ & $\begin{array}{c}\text { Maximum } \\
\text { Sweat Response } \\
\text { on Forearm } \\
(\mathrm{nl} / \mathrm{min})\end{array}$ & $\begin{array}{l}\text { No. of Glands } \\
\text { Stimulated } \\
\text { under Capsule }\end{array}$ & $\begin{array}{l}\text { Calculated } \\
\text { Mean Output } \\
\text { per Gland } \\
(\mathrm{nl} / \mathrm{min})\end{array}$ & $\begin{array}{l}\text { Apparent } \\
\text { Functional } \\
\text { Gland Density } \\
\text { (glands } / \mathrm{cm}^{2} \text { ) }\end{array}$ & $\begin{array}{l}\text { Estimated } \\
\text { Histological } \\
\text { Gland Density } \\
\text { (glands } / \mathrm{cm}^{2} \text { ) }\end{array}$ \\
\hline $\begin{array}{l}5 \text { infants } 2-4 \text { wk old } t \\
5 \text { infants } 6-18 \text { mth old } t \\
10 \text { healthy young adults }\end{array}$ & $\begin{array}{l}0 \cdot 25 \\
0 \cdot 52 \\
1 \cdot 51\end{array}$ & $\begin{array}{l}168 \pm 37 \\
404 \pm 77 \\
542 \pm 72\end{array}$ & $\begin{array}{r}106 \pm 9 \\
273 \pm 22 \\
90 \pm 6\end{array}$ & $\begin{array}{l}1 \cdot 6 \\
1 \cdot 5 \\
6 \cdot 0\end{array}$ & $\begin{array}{l}546 \pm 72 \\
348 \pm 28 \\
115 \pm 8\end{array}$ & $\begin{array}{r}1150 \\
580 \\
210\end{array}$ \\
\hline
\end{tabular}

^Estimated using the histological data employed to construct Fig. 3a.

tAll the babies had had lumbar meningomyeloceles repaired at birth. 
the age of 7 months and who had an extremely thin cerebral cortex, there was no sweat response to warmth or acetylcholine, though the pilomotor axon reflex was normal.

Meningocele. 2 full-term babies with a skincovered lumbar meningocele were studied in the second week of life. Sweat function appeared normal in these 2 babies and the sweat response to acetylcholine was in fact larger on the thigh than on the arm. One baby later developed hydrocephalus and had a valve inserted but sensation and motor function appear to be normal. These children are now 2 years old.

Meningomyelocele. 24 infants with lumbar meningomyelocele have been studied. Their ages ranged from 2 days to 18 months at the time of testing (average age 3 months). Surgical closure of the skin defect overlying the spine had been undertaken during the first 2 days of life and head circumference had been normal at this time, but a ventriculoatrial shunt became necessary to prevent progressive hydrocephalus in every case within the first 8 weeks of life. The infants were all assessed neurologically on more than one occasion during the first admission to hospital using methods similar to those of Stark and Baker (1967), and subsequent follow-up for a minimum of 12 months served to confirm and amplify the original assessment.

Sweat function on the arm appeared to be normal

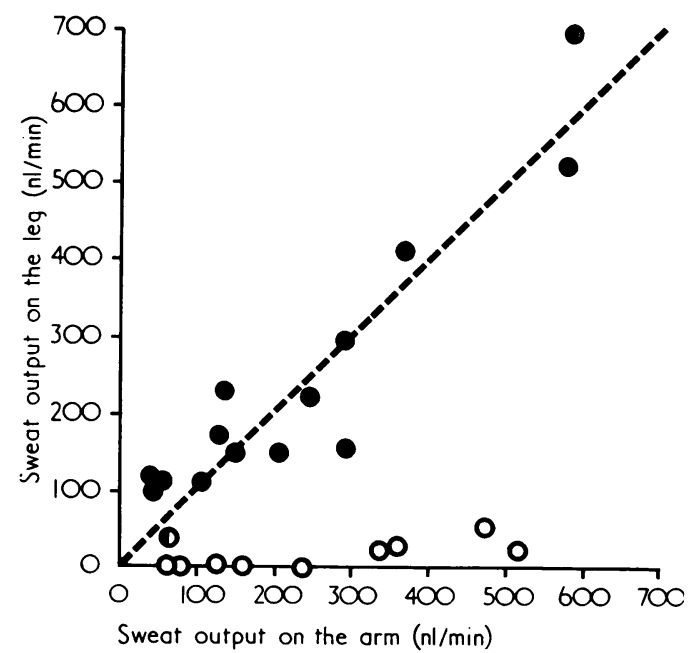

Fig. 2.-The sweat response on the arm and the leg after stimulation with $20 \mu \mathrm{g}$ acetylcholine in 24 infants who had lumbar meningomyeloceles at birth. Open symbols have been used to indicate the 9 infants whose legs were almost totally paralysed. in every case, but sweat function was frequently diminished below the level of the spinal lesion. In 4 infants there was no sweat response on the leg to either thermal or chemical stimulation though there was a clear pilomotor axon reflex; in a further 5 infants in whom no thermal response could be detected on the leg, the response to acetylcholine was less than one-tenth what it was on the arm (Fig. 2). These 9 infants had no detectable sensation and a complete flaccid paralysis below L2. There was some evidence of isolated reflex lower motor function in 2 of the babies.

In 14 infants the sweat response to acetylcholine on the leg did not differ from that on the arm by more than $50 \%$ (Fig. 2). These infants had moderate voluntary power in most of their leg muscles, and all but 2 had some perception of sensation down to at least L4; a clear thermal sweat response was present on the thighs of the older infants.

In one remaining baby (Fig. 2, symbol D) the response to acetylcholine was more equivocal, being only $40 \%$ on the leg what it was on the arm; this baby had little sensation below L3, badly imbalanced muscle groups, and very little effective motor innervation below L4.

\section{Discussion}

Normal physiology. It has long been realized that eccrine sweat gland density falls during childhood because no new glands form after birth. The histological evidence assembled in Fig. 3a suggests that about one-fifth of the glands have formed by the time the Japanese fetus has achieved a surface area of $0.05 \mathrm{~m}^{2}$, and that genesis is virtually complete 26 weeks after conception (surface area $\approx 0.1 \mathrm{~m}^{2}$ ). Comparable data are not available for children of other races, but the histological data collected by Pinkus (1964) and Szabó (1967) and the functional data of Thomson (1954) suggest that there are no important racial differences in gland density in adult life. The even distribution of the data about the linear relation in Fig. 3 seems to reflect variation in total sweat gland number rather than innaccurate counting.

Our counts of functional gland density on the forearm (Table II) fall well below the histological estimates provided by Fig. 3a, but a threefold decrease in density was found during growth after the first year of life, which parallels a similar increase in the surface area of the arm (Boyd, 1935). Our estimates of functional gland density are similar to those of Thomson (1954) who used the same method, but they are much lower than those obtained using a starch-iodine technique (Randall, 
1946; Huebner, Lobeck, and McSherry, 1966) or an oil immersion technique (Ogata, 1935; Kawahata, 1939). It seems, therefore, that the method we have employed fails to detect the very small amount of sweat produced by quite a number of glands. In this connexion it is, perhaps, not generally realized just how variable the eccrine sweat glands are in size, both during growth and in adult life (Takayama, 1954; Morita, 1955).

It is also possible that some sweat glands are totally functionless. Ogata (1935) was the first to provide experimental support for this view, and Kawahata $(1939,1950)$ the first to show that some glands may only develop any detectable function during the first two years of life. In fact, functional gland density measured using starch-iodine paper matches estimated histological gland density in adult life quite closely (Fig. 3), and there is little convincing evidence that many totally functionless glands exist on the forearm. Detailed analysis of the data obtained by Huebner et al. (1966) does, however, support the view of Kawahata that some glands only develop detectable function after birth (Fig. 3b).

Body temperature had an influence on the response to chemical stimulation. The effect was detectable in babies less than 2 weeks old (Foster et al., 1969a), but appeared to be much larger in adult subjects. In the latter, it was the maximum rate of gland secretion that appeared to increase at high temperature when, presumably, vasodilatation increased skin blood flow (Fig. 1a). Warming the skin is known to increase the sweat output of glands already responding to nervous stimuli, and it has been suggested that this may be because the amount of acetylcholine released at the neuroglandular junction is proportional to local skin temperature (MacIntyre et al., 1968); the present results indicate that local temperature also has an effect of the gland's response to direct chemical stimulation.

Although an attempt was made to perform each test under comparable conditions, no precautions were taken to keep the area of skin under examination at $36^{\circ} \mathrm{C}$; neither were the test solutions warmed to body temperature before use. As a result we have probably failed to demonstrate the maximum sweat potential of the glands under test (Foster, 1971). However, even without these precautions, the response to chemical stimulation

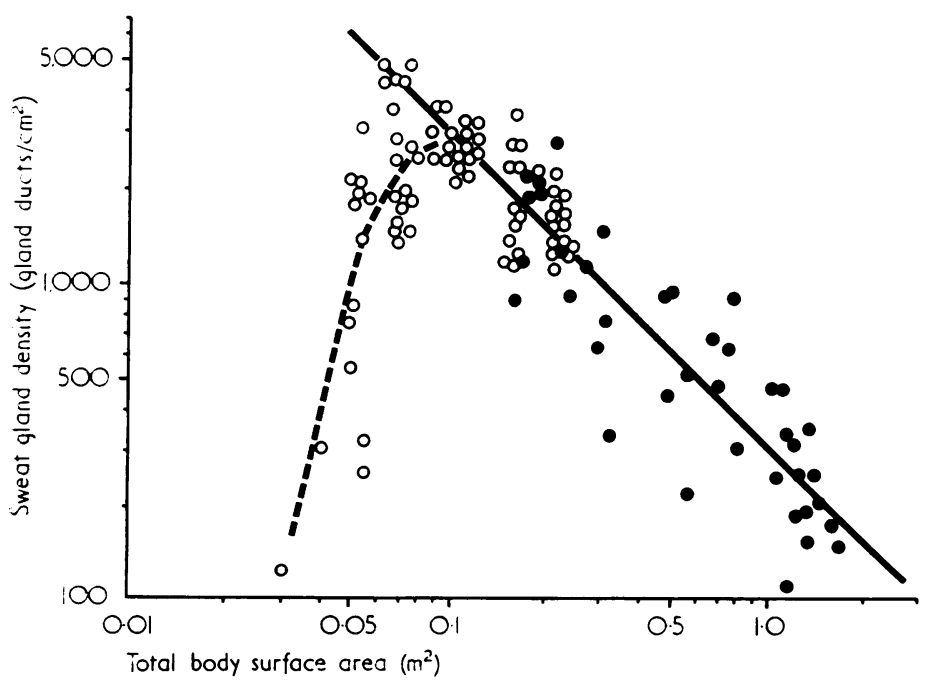

(a)

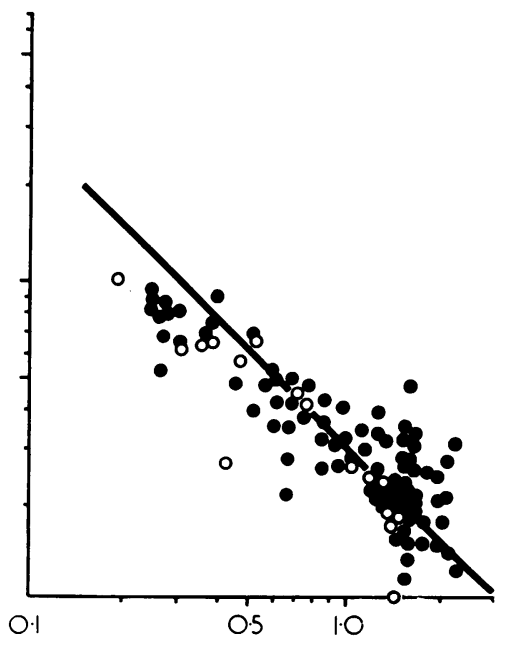

(b)

FIG. 3.-The relation between sweat gland density on the skin of the forearm and total body surface area (log scales). (a) Histological data from 39 Japanese children and adults (O) from the data of Koyama (1937), and from 78 Japanese fetuses (O) from the data of Taniguchi and Mochizuki (1937) and of Taniguchi and Kurita (1938). The regression line through the filled symbols is $y=311 x^{-0.94}$; the exponent $(-0.94 \pm 0.09)$ does not differ significantly from unity. (b) Data on functional sweat gland density for 97 American subjects (O) studied by Huebner et al. (1966), and for 16 Japanese subjects (O) studied by Kawahata (1939). The data for subjects more than 18 months old fall fairly evenly about the regression line derived from the histological data in (a). 
on the limbs exceeded the maximum response to thermal stimulation (with rectal temperature as high as $38^{\circ} \mathrm{C}$ ) in the young baby: in this respect the response of the newborn child differs significantly from that of the adult.

There are additional reasons for treating the present estimates of maximum output per gland with some reserve. In many of the younger babies most of the glands near the edge of the capsule were apparently unstimulated; this makes it very likely that some of the glands that did respond were only suboptimally stimulated. In the older subjects functional glands appeared to be evenly distributed throughout the area covered by the capsule, but studies with capsules of differing size suggested that, here too, some of the glands near the edge of the $1 \mathrm{~cm}$ capsule were only suboptimally stimulated. However, on the simplifying assumption that this failure to achieve uniform stimulation is largely balanced by the underestimation of functional gland density already noted, it can be deduced that there is probably about a fourfold rise in maximum output per gland with age (Table II). This rise is similar in magnitude to that seen by Huebner et al. (1966), and parallels the fourfold increase in mean gland size found by Takayama (1954) after birth. A fairly wellmarked increase in maximum sweat rate appears to occur during the first few days of life (Foster et al., 1969a), but maximum output per gland appears to change very little during the next 18 months.

As much as $20 \mu \mathrm{g}$ acetylcholine was necessary to produce a maximum response in the present study (Table I), but there is evidence that less than 0.1 $\mu \mathrm{g}$ is necessary to produce a maximum response in the adult if detailed attention is paid to such factors as skin temperature and capsule size (Foster, 1971). These factors have, by comparison, little effect on the minimum dose of acetylcholine necessary to stimulate sweat secretion; this dose appears to be about $1 \mathrm{ng}$ in adults, and such limited studies as have been performed to date suggest (Fig. 1) that the threshold may be much the same in the baby at term (c.f. Behrendt and Green, 1969).

Clinical application. The accurate assessment of sensory perception and voluntary motor ability in the neonate requires patience, skill, and experience, and tests for the integrity of the higher nervous centres are almost non-existent. Any clear-cut objective test of autonomic function has added value in this age group, and we believe that tests of sweat function may have some use in this respect. Anhidrosis can occur for many different reasons (Shelley, Horvath, and Pillsbury, 1950), but absence of thermal sweating is, nevertheless, a valuable sign of sympathetic dysfunction in man. The thermal sweat response may be difficult to detect and interpret in the newborn baby, but the response to direct chemical stimulation can be detected and interpreted with greater certainty.

Where there is a sympathetic postganglionic lesion, the denervation leads to loss of all response to chemical as well as thermal stimuli in adult man, though few structural changes can be detected in the sweat glands on histological examination (Silver, Montagna, and Versaci, 1964). The sweat glands are thus an exception to Cannon's 'Law of denervation', for denervation of an organ usually leads to increased sensitivity (Cannon, 1939).

However, the developmental lesion was in the brain or spinal cord of all the babies we studied and the defect was thus presumably preganglionic. It was not possible to test the function of the postganglionic fibres supplying the sweat glands, but the presence of a normal pilomotor axon reflex in the skin showed that some at least of the postganglionic sympathetic nerve fibres were functional. When an adult suffers a preganglionic sympathetic nerve lesion, the regional sweat response to chemical stimulation is generally retained though the thermal response is lost (Hyndman and Wolkin, 1941; Chalmers and Keele, 1952). We have recently been led to doubt the universality of this distinction between the effect of pre- and postganglionic damage because in a number of children with severe long-standing brain damage due to trauma, anoxia, septicaemia, or progressive encephalopathy the sweat glands failed to respond to chemical stimulation (unpublished data). Nevertheless, the absence of a response to chemical stimulation at term in some of the babies with defects of the spine and central nervous system seems to imply that full functional maturation of the eccrine sweat glands depends on intact and normal preganglionic innervation during development in utero.

If this is so then the demonstration of a positive sweat response to local stimulation with acetylcholine has a certain diagnostic value. The variability of the response in the babies with lumbar meningomyelocele seems to reflect a difference in the extent to which the developmental lesion had damaged the relevant spinal tracts. The sympathetic innervation of the skin does not have quite the same well-marked dermatome pattern as the sensory innervation; there is, nevertheless, the same general relation, and it is worth noting that the cord lesion appeared to affect sensory function, motor function, and sweat function to much the same extent in all 24 babies we studied. 
In children with severe developmental defects of the brain itself there was often a complete or almost complete anhidrosis. 8 such babies died; in each case the basal ganglia and brainstem were found to be badly disorganized at necropsy. The hypothalamus is thought to be involved in the central regulation of body temperature in man, as in animals, so it seems reasonable to conclude that the thermoregulatory centres, or the tracts leading to them, had been involved in the congenital defect in these babies. In the babies we have studied, in whom developing hydrocephalus was successfully controlled with a valve and a ventriculoatrial shunt, sweat function always remained normal (at least, that is, above the level of any associated spinal defect). The 4 term babies who had an abnormally large head circumference at birth were, however, almost totally anhidrotic, as were 4 older children in whom severe unarrested hydrocephalus occurred as a result of late diagnosis or failure of the shunt mechanism (unpublished data). This latter finding is in keeping with the observation of Gubbay (1967) that temperature regulation is not infrequently defective in children with unrelieved obstructive hydrocephalus. Follow-up assessment of the 50 children we have studied indicates that the prognosis for children with total anhidrosis is extremely gloomy: 8 of the 13 anhidrotic children we studied are already dead and the remaining 5 show serious mental retardation. We speculate that simplinied tests of sweat function probably have prognostic value in the assessment of certain babies with severe congenital defects of the central nervous system. The possibility certainly merits further prospective study.

Four infants with congenital defects of the brain had no ability to sweat over the general body surface to either thermal or chemical stimulation when more than 12 weeks old, but some sweat could be seen on the bridge of the nose and the upper lip when these babies became restless, miserable, and hot. In one infant there was also evidence of sweating on the palms. This localized response is characteristic of sweating that is emotional rather than thermal in origin, as is the response that can often be obtained from the soles of the feet. Uchino (1939a, b) found that this type of emotional response could usually be detected in infants for the first time between 1 and 3 months after birth. Kuno (1956) undertook numerous studies on one subject who had an encephalitis in infancy and who had a similarly limited pattern of sweating when 18 years old. We did not examine sweat function on the hands or feet of any of the infants we studied. However, should further study confirm that sweat function does normally persist at these sites in subjects with generalized anhidrosis, this would explain the unexpected report that sweat can nearly always be detected on the soles of the feet of children with paralysis of the legs as a result of a meningomyelocele (Porter, 1968).

We conclude that the absence of a sweat response to direct chemical stimulation in a term infant at birth suggests the presence of a congenital defect involving the sympathetic nerves or their associated tracts in the spinal cord or brain stem. Where there is a known developmental defect of the brain and the whole body is anhidrotic (with the possible exception of the regions noted above), there are reasonable grounds for concluding that the basal ganglia or brainstem are seriously disorganized.

We are grateful to the paediatricians and surgeons of The London Hospital, Whitechapel, Queen Elizabeth Hospital for Children, Hackney, and Queen Mary's Hospital for Children, Carshalton, for the opportunity to study these children, and to the pathologists for their detailed necropsy reports.

\section{REFERENCES}

Behrendt, H., and Green, M. (1969). Drug-induced localized sweating in full-size and low-birth weight neonates. American Fournal of Diseases of Children, 117, 299.

Boyd, E. (1935). The Growth of the Surface Area of the Human Body, p. 119 . University of Minnesota Press, Minneapolis.

Cannon, W. B. (1939). A law of denervation. American fournal of the Medical Sciences, 198, 737.

Chalmers, T. M., and Keele, C. A. (1952). The nervous and chemical control of sweating. Brtish fournal of Dermatology, 64, 43.

Coon, J. M., and Rothman, S. (1940). The nature of the pilomotor response to acetylcholine; some observations on the pharmacodynamics of the skin. Fournal of Pharmacology and Experimental Therapeutics, 68, 301.

Cross, K. W., Hey, E. N., Kennaird, D. L., Lewis, S. R., and Urich, H. (1971). Lack of temperature control in infants with abnormalities of central nervous system. Archives of Disease in Childhood, 46, 437.

Foster, K. G. (1971). Factors affecting the quantitative response of human eccrine sweat glands to intradermal injections of acetylcholine and methacholine. Fournal of Physiology, 213, 277.

Foster, K. G., Hey, E. N., and Katz, G. (1968). Eccrine sweat gland function in the new-born baby. Fournal of Physiology, 198, 36P.

Foster, K. G., Hey, E. N., and Katz, G. (1969a). The response of the sweat glands of the new-born baby to thermal stimuli and to intradermal acetylcholine. Fournal of Physiology, 203, 13.

Foster, K. G., Hey, E. N., and O'Connell, B. (1969b). Sweat function in babies with defects of the central nervous system. Developmental Medicine and Child Neurology, Suppl., 20, 94.

Foster, K. G., and Weiner, J. S. (1967). The continuous monitoring of sweat secretion of man and cat using a ventilated capsule and an infra-red analyser. Fournal of Physiology, 191, 1P.

Gibson, L. E., and Cooke, R. E. (1959). A test for concentration of electrolytes in sweat in cystic fibrosis of the panoreas utilizing pilocarpine by iontophoresis. Pediatrics, 23, 545.

Green, M., and Behrendt, H. (1969). Sweating capacity of neonates. Nicotine-induced axon reflex sweating and the histamine flare. American fournal of Diseases of Children, 118, 725.

Green, M., and Behrendt, H. (1970). Drug-induced localized sweating in neonates. Responses to exogenous and endogenous acetylcholine. American fournal of Diseases of Children, 120, 434. 


\section{Sweat Function in Babies with Defects of the Central Nervous System}

Gubbay, S. S. (1967). Derangement of temperature control in hydrocephalus. Developmental Medicine and Child Neurology, Suppl. 13, 125.

Hey, E. N., and Katz, G. (1969). Evaporative water loss in the new-born baby. Fournal of Physiology, 200, 605.

Huebner, D. E., Lobeck, C. C., and McSherry, N. R. (1966). Density and secretory activity of eccrine sweat glands in patients with cystic fibrosis and in healthy controls. Pediatrics, 38, 613 .

Hyndman, O. R., and Wolkin, J. (1941). The pilocarpine sweating test. I. A valid indicator in differentiation of preganglionic and postganglionic sympathectomy. Archives of Neurology and Psychiatry, 45, 992.

Kawahata, A. (1939). Variation in the number of active human sweat glands with age. (In Japanese.) Nippon Seirigaku Zasshi, 4, 438 .

Kawahata, A. (1950). Studies of the function of the human sweat organs. (Report 1.) Fournal of the Mie Medical College, 1, 25.

Kōyama, K. (1937). UUber die Verteilung der Schweissdrüsen bei der Japanern. Okajimas Folia Anatomica faponica, 15, 571.

Kuno, Y. (1956). Human Perspiration, Chapter 13, p. 347. C. Thomas, Springfield, Illinois.

MacIntyre, B. A., Bullard, R. W., Banerjee, M., and Elizondo, R. (1968). Mechanism of enhancement of eccrine sweating by localised heating. Fournal of Applied Physiology, 25, 255.

Morita, S. (1955). Quantitative Untersuchung der Schweissdrüsen bei den japanischen Feten. Okajimas Folia Anatomica faponica, 27, 81.

Ogata, K. (1935). Functional variations in human sweat glands, with remarks upon the regional difference in the amount of sweat. (In Japanese). Fournal of Oriental Medicine, 23, 1155. (See also English abstract, p. 98.)

Pinkus, H. (1964). Die makroskopische Anatomie der Haut. In Handbuch der Haut und Geschlechtskrankheiten. Ed. by J. Jadassohn. Erganzungswerk, vol. I, pt. 2, p. 12. Ed. by A. Marchionini. Springer, Berlin.

Porter, R. W. (1968). Vasomotor control in the lower limbs of children with meningomyeloceles. Developmental Medicine and Child Neurology, Suppl., 15, 62 .

Randall, W. C. (1946). Quantitation and regional distribution of sweat glands in man. Fournal of Clinical Investigation, 25, 761.

Rothman, S., and Coon, J. M. (1940). Axon reflex responses to acetylcholine in the skin. Fournal of Investigative Dermatology, $3,79$.

Shelley, W. B., Horvath, P. N., and Pillsbury, D. M. (1950) Anhidrosis. An etiologic interpretation. Medicine, 29, 195.

Silver, A., Montagna, W., and Versaci, A. (1964). The effect of denervation on sweat glands and Meissner corpuscles of human hands. Fournal of Investigative Dermatology, 42, 307.

Stark, G. D., and Baker, G. C. W. (1967). The neurological involvement of the lower limbs in myelomeningocele. Developmental Medicine and Child Neurology, 9, 732.

Sutarman, and Thomson, M. L. (1952). A new technique for enumerating active sweat glands in man. Fournal of Physiology, $117,51 P$.

Szabó, G. (1967). The regional anatomy of the human integument with special reference to the distribution of hair follicles, sweat glands and melanocytes. Philosophical Transactions of the Royal Society of London, B, 252, 447.

Takayama, F. (1954). Quantitative Untersuchung der Schweissdrüsen bei den Menschen, insbesondere über cie Veränderung der Schweissdrüsen nach der Geburt. Okojimas Folia Anatomica faponica, 26, 31.

Taniguchi, T., and Kurita, Y. (1938). Über die Verteilung der Schweissdrüsen bei den japanischen Zwillingsfeten. Okajimas Folia Anatomica faponica, 17, 297.

Taniguchi, T., and Mochizuki, D. (1937). Über die Verteilung der Schweissdrüsen bei den japanischen Feten. Okajimas Folia Anatomica faponica, 15, (Suppl.), 265.

Thomson, M. L. (1954). A comparison between the number and distribution of functioning eccrine sweat glands in Europeans and Africans. Fournal of Physiology, 123, 225.

Uchino, S. (1939a). Studien über die Schweisssekretion der Neugeborenen. Fapanese fournal of Obstetrics and Gynecology, 22, 9.

Uchino, S. (1939b). Sweating function of newborn babies. (In Japanese.) Sanka Fujinka Kiyo, 22, 238.

Correspondence should be addressed to The Secretary, M.R.C. Environmental Physiology Unit, London School of Hygiene and Tropical Medicine, Keppel Street, London W.C.1. 